\title{
Maternal Weight and Sire Group, Not Caloric Intake, Influence Adipocyte Volume in Infant Female Baboons
}

\author{
DOUGLAS S. LEWIS, ANTHONY M. COELHO, JR., AND EVELYN M. JACKSON \\ Department of Physiology and Medicine, Southwest Foundation for Biomedical Research, \\ San Antonio, Texas 78228-0147
}

\begin{abstract}
We tested the hypothesis that overfeeding with a high caloric (concentrated) formula increases growth without influencing adipocyte volume in preweaning infant baboons. Female infant baboons from three sires and 25 dams were fed either $67.5 \mathrm{kcal}$ (normal formula) or 94.5 kcal (concentrated formula) $/ \mathbf{1 0 0} \mathrm{g}$ Similac formula. Immediately before weaning (19 wk), adipocyte volume was measured in biopsied adipose tissue from omentum, flank, and popliteal depots. From birth until weaning, infants fed the concentrated formula consumed $20 \%$ more total calories, averaged $15 \%$ more calories $/ \mathrm{kg} / \mathrm{wk}$, and gained $14 \%$ more weight than normally fed infants. Adipocyte volume differed significantly among different sites (omentum > popliteal $>$ flank) and among different sire groups. Increased caloric intake alone did not increase adipocyte volume. There was a small but significant sire by infant formula interaction on adipocyte volume. When fed the concentrated formula, progeny from one sire had larger adipocytes than normally fed infants, whereas progeny from the other two sires had smaller adipocytes or adipocytes that were comparable to infants fed normal formula. Variability in adipocyte volume at 19 wk of age was best accounted for by maternal weight and sire group (omentum $R^{2}=0.334, p=0.026$; flank $R^{2}=0.532, p=0.01$; popliteal $R^{2}=0.482, p=0.01$ ) and not by caloric intake. These results suggest that the level of triglyceride deposition into adipocytes attained during preweaning growth is determined to a greater extent by genetic and other factors rather than caloric intake. (Pediatr Res 30: 534-540, 1991)
\end{abstract}

Abbreviations

ANOVA, analysis of variance

During the first months of life, adipose tissue accounts for as much as $40 \%$ of the total weight gained by human infants (1). The extent to which overnutrition and genetic factors influence the rapid increase in fat mass during infancy is not clear. The conventional wisdom is that infant overfeeding results in obese infants, yet there is conflicting evidence whether infant overnutrition results in obese or even moderately fatter infants. Studies that suggest that overfeeding results in infant obesity are based primarily on increased weight gain and skinfold thicknesses in prematurely weaned and formula fed infants $(2-5)$. Other studies

Received January 30, 1991; accepted July 16, 1991.

Correspondence: Douglas S. Lewis, Ph.D., Department of Physiology and Medicine, Southwest Foundation for Biomedical Research, P. O. Box 28147, San Antonio, TX 78228-0147.

Supported by Grant HD-23327 from the National Institute of Child Health and Human Development. suggest that behavior and genetic factors that result in low energy expenditure, not caloric intake, influence infant obesity (6-9). Dwyer and Mayer (10) proposed that overnutrition during infancy increases growth of lean tissues and not fat in the infant.

The baboon is an appropriate model to investigate factors that influence fat development during the preweaning period of life because baboons can be reared on commercial human infant formulas and because fat mass increases from approximately 20 $\mathrm{g}(2 \%$ of body weight) at birth to well over $200 \mathrm{~g}$ (about $15 \%$ of body weight) at weaning (11). In a previous study, infant baboons fed a concentrated formula gained more fat and had larger fat cells at weaning than infants fed a diluted formula (12). However, the effects of concentrated formula on fat mass and adipocyte volume during infancy relative to normal feeding are not known. Female baboons, and to a lesser extent male baboons, overfed with a concentrated formula as infants had significantly greater fat mass and adipocyte volume as young adults than baboons fed normally as infants $(13,14)$.

In the current experiment we determined the relative roles of sire group, maternal weight, and caloric intake (concentrated and normal formula) on adipocyte volume in female infant baboons.

\section{MATERIALS AND METHODS}

Experimental design. Twenty-five female infant baboons ( $\mathrm{Pa}$ pio cynocephalus) were produced by the matings of three sires with 25 dams. Characteristics of the sires used for breeding in the current study are summarized in Table 1. Baboons X1337 and X2088 were selected as sires based on body fat characteristics of their paternal half-siblings as determined in a previous study $(13,14)$. The young adult paternal half-siblings of X1337 were considerably leaner ( $4 \pm 1 \%$ body weight as fat, $n=6$ ) than paternal half-siblings of sire X2088 $(9 \pm 2 \%$ body weight as fat $)$. The third sire (X2387) was chosen randomly with consideration for breeding capability. All the dams were randomly selected based on breeding capability. Newborn females were assigned at birth to either the normal formula group $(n=13)$ or to the concentrated formula group $(n=12)$. One infant contracted an intestinal infection and was deleted from the study. All infants were fed four times a day at $0700,1000,1300$, and $1515 \mathrm{~h}$ until 19 wk of age. Caloric intake was measured by weighing the bottle containing formula before and after each feeding.

The experimental protocol was approved by the Animal Research Committee of the Southwest Foundation for Biomedical Research, which is fully accredited by the American Association for Accreditation of Laboratory Animal Care.

Diets. Sires and dams were fed regular monkey diet $(8715-00$; Wayne Pet Food Division, Chicago, IL), which contains $31 \%$ of calories as protein, $62 \%$ of calories as carbohydrate, and $7 \%$ of calories as fat. Normal formula infants were allowed to consume Similac formula (Ross Laboratories, Columbus, $\mathrm{OH})(67.5 \mathrm{kcal} /$ 
Table 1. Physical characteristics of sires

\begin{tabular}{cccc}
\hline Sire & $\begin{array}{c}\text { Age } \\
(\mathrm{y})\end{array}$ & $\begin{array}{c}\text { Weight* } \\
(\mathrm{kg})\end{array}$ & $\begin{array}{c}\text { Adipocyte } \\
\text { volume† } \\
(\mathrm{nL})\end{array}$ \\
\hline X1337 & 12 & $33.5 \pm 1.7$ & 0.157 \\
X2088 & 11 & $26.4 \pm 1.4$ & 0.667 \\
X2378 & 11 & $29.9 \pm 1.8$ & 0.310 \\
\hline
\end{tabular}

* Mean $\pm \mathrm{SD}$ weight for $3 \mathrm{y}$ preceding breeding for the current experiment (at least seven measurements).

$\dagger$ Mean adipocyte volume of the omentum, flank, and popliteal depots.

$100 \mathrm{~g}$ formula) ad libitum within a four-meal framework. Infants fed in this manner gain weight similarly to breast-fed infants (13). Similac formula contains $9.2 \%$ of calories as protein, $43.1 \%$ as carbohydrate, and $48.5 \%$ as fat. Infants fed the concentrated formula $(94.5 \mathrm{kcal} / 100 \mathrm{~g}$ Similac formula) were offered the same volume of formula as normally fed infants.

Infant formulas were prepared by diluting seven parts of concentrated Similac formula (Ross Laboratories, Columbus, $\mathrm{OH})$ with either seven parts water $(67.5 \mathrm{kcal} / 100 \mathrm{~g}$, normal formula) or three parts water $(94.5 \mathrm{kcal} / 100 \mathrm{~g}$, concentrated formula). The infant formulas were fed until the day of the fat depot biopsy.

Measurement of adipocyte volume. Adipose tissue biopsies were obtained from 19-wk-old infants. Immediately before weaning, infants were immobilized with ketamine $(10 \mathrm{mg} / \mathrm{kg}$ mass $)$ and anesthetized with a mixture containing xylazine $(0.5 \mathrm{mg}$ / $\mathrm{kg})$, atropine sulfate $(0.01 \mathrm{mg} / \mathrm{kg})$, acepromazine $(0.08 \mathrm{mg} / \mathrm{kg})$, ketamine $(3.75 \mathrm{mg} / \mathrm{kg})$, and isofluorane. Approximately $100 \mathrm{mg}$ of adipose tissues were obtained by biopsy from the omentum (visceral) and the flank and popliteal (s.c.) depots. Adipose tissue was placed immediately into saline at $37^{\circ} \mathrm{C}$, washed, minced, and treated with collagenase for $1 \mathrm{~h}$ at $37^{\circ} \mathrm{C}$. The mean diameter of isolated adipocytes was measured as described by DiGirolamo et al. (15). Mean adipocyte volume was calculated assuming that the isolated adipocytes were spheres.

Estimation of adiposity. Total body fat was not measured directly in the current study. We used the ratio of the mean adipocyte volume from the three different sites to body weight as an index of relative fatness or adiposity. We evaluated adipocyte volume as an indicator of fat depot mass, total body fat mass, and adiposity using data previously reported from 24 (12 male and 12 female) 18-wk-old baboons fed diluted and concentrated Similac formula (12). Using these data (12), adipocyte volume was strongly associated with directly measured total body fat mass $(r=0.867, p=0.0001)$ at $18 \mathrm{wk}$ of age, whereas the number of adipocytes was not associated $(r=0.125)$ with total body fat mass. In other words differences in body fat mass in infant baboons at $18 \mathrm{wk}$ of age are directly reflected by the volume of adipocytes and not adipocyte number. Indeed, adipocyte volume is the best predictor of total body fat compared with morphometric measures (16) or body mass index based on weight and length (Lewis, D, unpublished observations). The utility of adipocyte volume to reflect adiposity of female infant baboons is illustrated in Figure 1. Adiposity estimated from mean adipocyte volume of the omentum, flank, and popliteal depots divided by body weight in 14 necropsied baboons from two previous studies (12; Lewis $\mathrm{D}$, unpublished observations) was strongly associated with adiposity that was directly measured in the same baboons by extraction and quantification of total body fat mass.

Morphometric and urinary creatinine measurements. Measurements were obtained of neck skinfold thickness and the crownrump length as described previously (17). Crown-rump length was measured with an anthropometer. Neck skinfold thickness was measured with a Holtain skinfold caliper and recorded to the nearest $0.1 \mathrm{~mm}$. We previously demonstrated that neck skinfold thickness is significantly associated with fat mass and

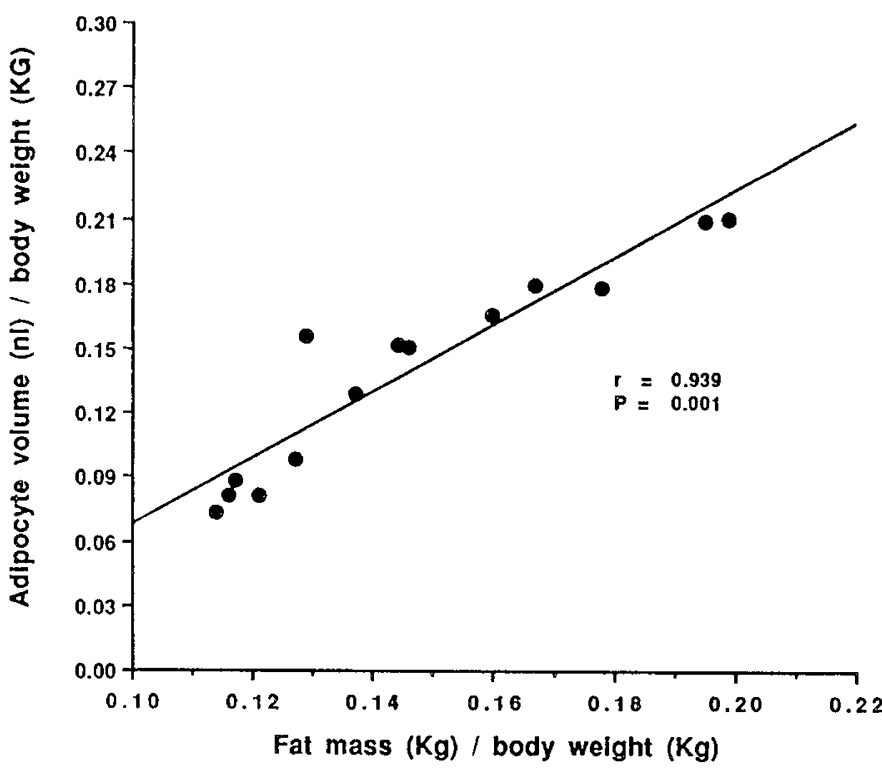

Fig. 1. Relationship between mean adipocyte volume and total body fat mass in 18-wk-old female baboons. Total body fat was measured directly in necropsied animals (14) and compared with mean adipocyte volume (mean value from the combined omental, flank, and popliteal depots) measured in the same animals.

crown-rump length is significantly associated with lean mass in infant baboons (16).

Urine was collected on ice over two successive 24-h periods when infants were 7 and 17 wk old. Creatinine was determined using a diagnostic kit (no. 555-A, colorimetric; Sigma Chemical Co., St. Louis, MO). Duplicate samples from each collection were analyzed, and the mean total creatinine values from the two 24-h collection were averaged for analysis.

Statistical analysis. Data obtained between birth and $18 \mathrm{wk}$ were analyzed by ANOVA for repeated measures using a linear model that included the main effects of the preweaning diet and sire and preweaning diet by sire interaction. Trial factors included age and time where appropriate. Analysis of residuals revealed no violations of the assumptions of the ANOVA. The multivariate $F$ was used to determine the level of significance.

Adipocyte volume and adiposity at $19 \mathrm{wk}$ of age were analyzed by ANOVA with sire, infant formula (normal and concentrated), and site (omentum, flank, and popliteal) as independent variables. Fat cell volume and adiposity data were log transformed before analysis to better satisfy the assumptions of the model.

Multiple means were compared (a posteriori) using the Tukey Honestly Significance Difference Test.

Associations of infant weight gain and adipocyte volume with sire group, maternal weight (mean nonpregnant weight over the $3 \mathrm{y}$ before breeding for this study), and caloric intake were analyzed using multiple linear regression (18).

Although significance was set at $p<0.05$, we have also reported differences with $p$ values $<0.1$ to better balance the type I and type II statistical errors.

\section{RESULTS}

Effect of infant formula and sire on caloric intake and weight gain. Two infants fed the concentrated formula reduced the volume of formula intake such that their caloric intake (27 534 $\pm 339 \mathrm{kcal})$ and weight gain $(984 \pm 28 \mathrm{~g})$ were similar to those of infants fed normal formula. These infants were excluded from the data analysis for infant formula effects on caloric intake and weight gain because they failed to overeat. Ten of 12 infants fed the concentrated formula consumed $20 \%$ more total calories from birth to $18 \mathrm{wk}$ than infants fed normally $(33678 \pm 673$ versus $28013 \pm 709 \mathrm{kcal}, p=0.001)$. The difference in caloric 
intake between infants fed normal formula and those overfed with the concentrated formula was greater during the first $8 \mathrm{wk}$ $(26 \%)$ compared with the last $10 \mathrm{wk}(18 \%)$. The mean caloric intakes $/ \mathrm{kg} / \mathrm{wk}$ and weight gain of the infants fed normal formula and those overfed with the concentrated formula are presented in Figure 2. During the preweaning period, infants overfed with the concentrated formula consumed an average of $15 \%$ more calories $/ \mathrm{kg} /$ wk than infants fed normal formula (Fig. $2 A, p=$ 0.003).

During the preweaning period, infants overfed with the concentrated formula $(n=10)$ gained significantly more weight from birth to weaning at $19 \mathrm{wk}$ than normally fed infants (Fig. $2 B, p$ $=0.001$ ).

There was neither a significant sire effect nor a sire by infant formula interaction on infant weight gain or caloric intake.

Effect of infant formula, sire, and depot site on adipocyte volume. Overfeeding with a concentrated formula compared with feeding normal formula had no effect on mean adipocyte volume from all three depot sites (normal formula $=0.33 \pm 0.02 \mathrm{~nL}$ and concentrated formula $=0.34 \pm 0.03 \mathrm{~nL}$ ). The effect of infant formula was similar among the three different fat depot sites (data not presented). There was a small but significant sire by
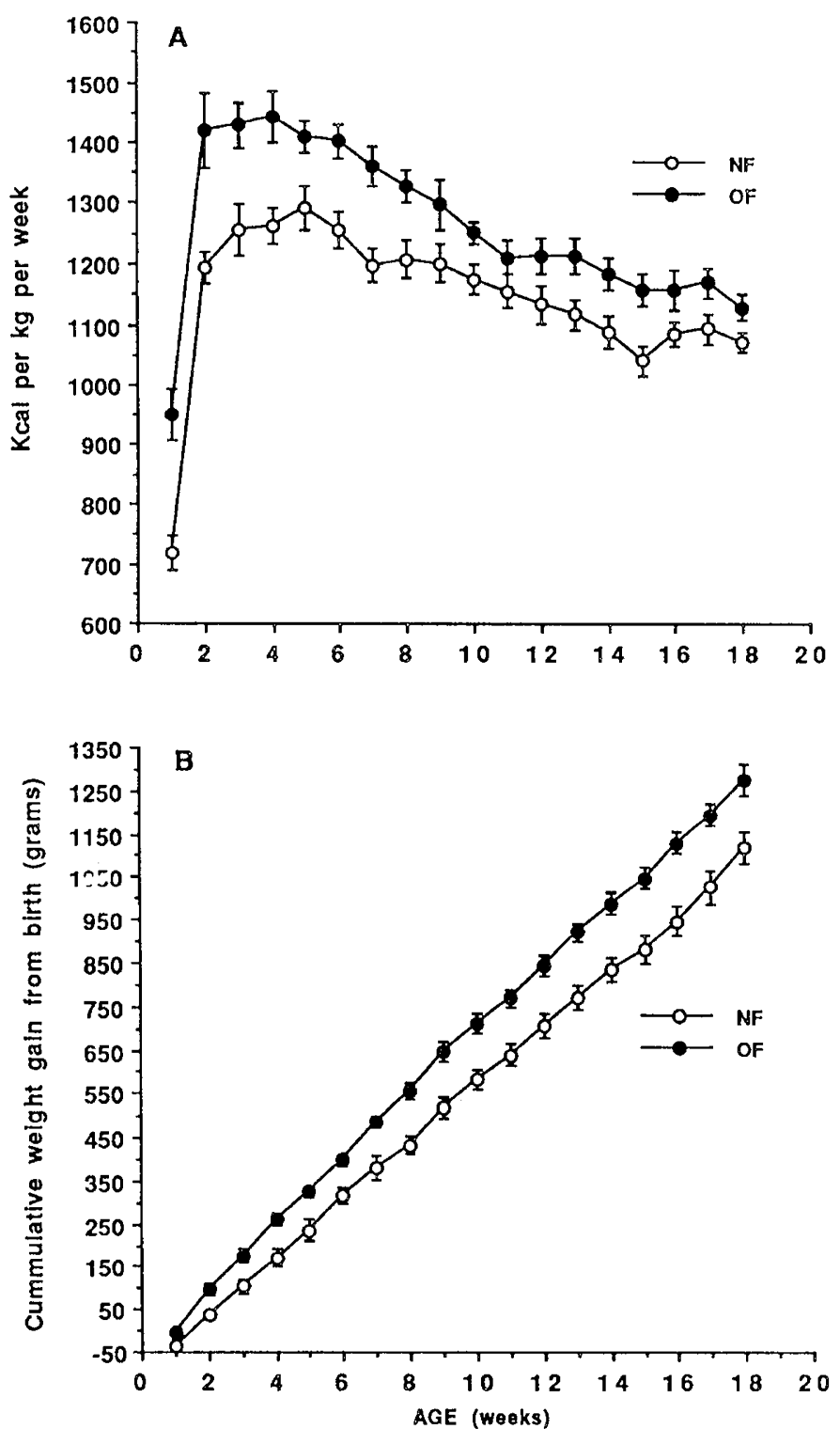

Fig. 2. Caloric intake and weight gain by infant diet and age. Values presented are means \pm SEM. The open symbols represent normally fed infants and the closed symbols represent overfed infants. formula interaction ( $p=0.043$ ) on adipocyte volume: when overfed with the concentrated formula, progeny from sire X1337 had slightly larger adipocytes, whereas progeny from X2088 had smaller adipocytes and progeny from X2378 had similar sized adipocytes compared with normally fed infants (Fig. 3).

The mean adipocyte volumes by depot site and sire group are presented in Figure 4. Adipocyte volume varied by site (omental adipocyte volume $>$ popliteal adipocyte volume $>$ flank adipocyte volume, $p=0.035$ ), but the differences were small. The differences in adipocyte volume among depots were not influenced by sire group.

Adiposity was estimated as the ratio of mean adipocyte volume and body weight. As was the case with adipocyte volume, infant formula had no significant effect on infant adiposity (normal formula $=0.173 \pm 0.015$ and concentrated formula $=0.154 \pm$ 0.008 ), but there was a sire effect on infant adiposity (progeny of sire X1337 $=0.12 \pm 0.02$, progeny of sire X2088 $=0.17 \pm 0.01$, and progeny of sire $\mathrm{X} 2378=0.20 \pm 0.02, p=0.035$ ). There was no significant sire by infant formula interaction on adiposity.

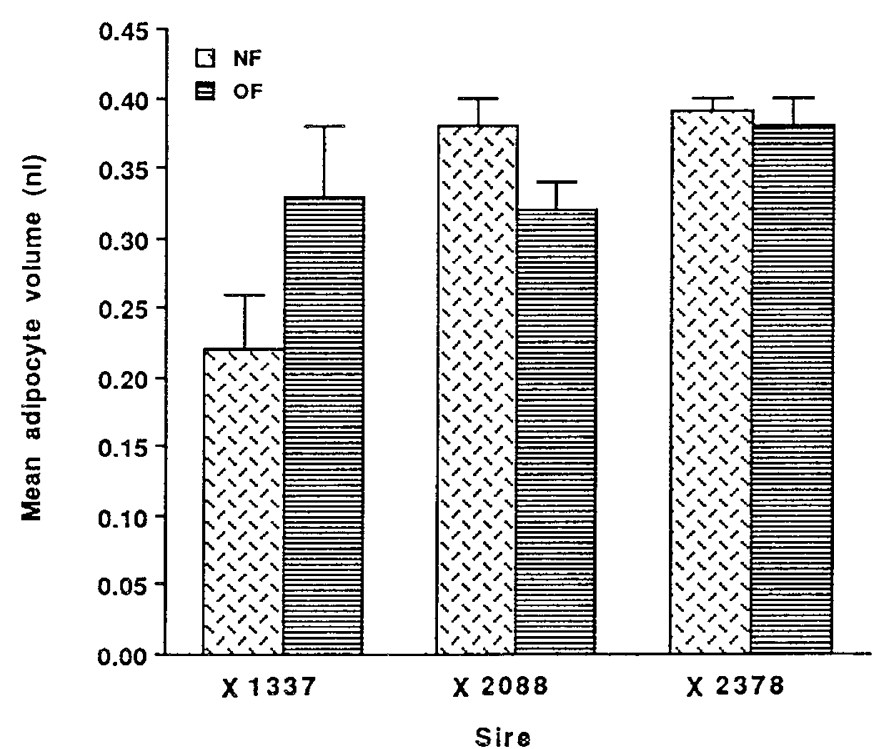

Fig. 3. Mean adipocyte volume by infant diet and sire. Values are means \pm SEM. Mean adipocyte volume is the mean from the combined omental, flank, and popliteal depots.

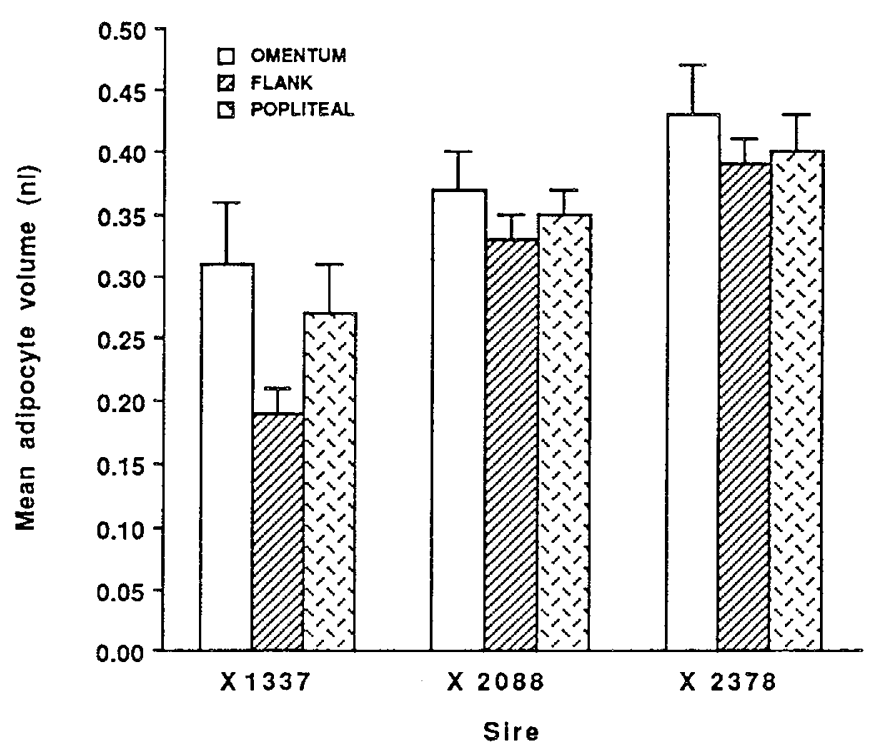

Fig. 4. Mean adipocyte volume by region and sire. Values are means \pm SEM. 
Effect of infant formula and sire on urinary creatinine excretion, crown-rump length, and neck skinfold thickness. The mean urinary creatinine excretion (measured at 7 and $17 \mathrm{wk}$ ) and the increase in crown-rump length and neck skinfold thickness from birth to $18 \mathrm{wk}$ of age of infants overfed with concentrated formula and those fed normally are presented by sire groups in Table 2 . The excretion of both total urinary creatinine and urinary creatinine $/ \mathrm{kg}$ body mass increased with age $(p=0.001)$, but this age-related increase was not influenced by infant formula nor by sire (data not presented). Infants overfed with the concentrated formula excreted more total creatinine per day $(390 \pm 10$ versus $350 \pm 20 \mu \mathrm{mol}$ creatinine, $p=0.08$ ) and total creatinine $/ \mathrm{kg}$ body mass $(240 \pm 5$ versus $200 \pm 5 \mu \mathrm{mol}$ creatinine $/ \mathrm{kg} / \mathrm{d}, p=0.026)$ than infants fed normal formula. There was a significant difference in both total creatinine and creatinine $/ \mathrm{kg}$ body mass among progeny from different sires $(p=0.034)$. Progeny of sire X 1337 excreted more total creatinine and more creatinine $/ \mathrm{kg}$ body weight than progeny from either X2088 or X2378.

Overfeeding with concentrated formula did not significantly affect the increase in either the neck skinfold thickness or the crown-rump length from birth to $18 \mathrm{wk}$ of age compared with feeding with normal formula (Table 2). However, there was a significant sire by infant formula interaction $(p=0.042)$ on crown-rump length during the preweaning period. When overfed with the concentrated formula, progeny from sires X2088 and X2378 had a greater increase in crown-rump length from birth to $18 \mathrm{wk}$ of age than normally fed infants. Among sire X1337 progeny, those infants overfed with the concentrated formula had a smaller increase in crown-rump length than infants fed normal formula.

Relationships of preweaning weight gain and adipocyte volume with caloric intake and maternal weight. Multivariate analysis was used to evaluate the relationships of caloric intake, sire group, and maternal weight with preweaning weight gain and adipocyte volume. All 24 infants were used in these analyses. The best prediction model for weight gain included only total caloric intake (Fig. $5, R^{2}=0.767, p=0.001$ ). Addition of birth weight, maternal weight, or sire group with total caloric intake did not significantly increase the prediction of preweaning weight gain. The strong association of preweaning weight gain with total caloric intake is in part due to increased formula intake by larger infants. Caloric intake $/ \mathrm{kg}$ body mass may be a more meaningful predictor of weight gain. When average caloric intake $/ \mathrm{kg}$ body mass/wk was used in place of total caloric intake, the best model $\left(R^{2}=0.458, p=0.016\right)$ to predict weight gain included the average caloric intake $/ \mathrm{kg}$ body mass $/$ wk (partial coefficient $=$ $0.623, p=0.001$ ), birth weight (partial coefficient $=0.419, p=$ 0.041 ), maternal weight (partial coefficient $=0.366, p=0.079$ ), and sire group (partial coefficient $=0.513, p=0.01$ ). With this model, stepwise regression analysis revealed that preweaning caloric intake $/ \mathrm{kg}$ body weight accounted for most of the variability in infant weight gain.

Mean adipocyte volume is not related to total caloric intake (Fig. 6) or to caloric intake/kg body weight (data not presented) among all the infants studied. Adipocyte volume in each individual fat depot was also not related to infant caloric intake. The results of the best multivariate models to predict omental and s.c. adipocyte volumes are summarized in Table 3. Omental, flank, and popliteal adipocyte volumes were best predicted by maternal weight and sire. Addition of total caloric intake or caloric intake $/ \mathrm{kg}$ body mass as a predictor variable to the multivariate analysis had no significant effect on the prediction of adipocyte volume. The relationship (adjusted for sire group and caloric intake) of maternal weight with the infant mean adipocyte volume at $19 \mathrm{wk}$ of age is presented in Figure 7.

\section{DISCUSSION}

Influence of infant overfeeding on adipocyte volume in infant baboons. The results reported here confirm the hypothesis that in infant female baboons overfeeding with a high caloric formula during the preweaning period does not increase adipocyte volume relative to feeding normal formula. These results and those of our previous study (11) with underfed and overfed infants demonstrate that caloric intake during the preweaning period has little if any influence on how much adipose tissue female infant baboons develop. When underfed with a diluted Similac formula, female infants had smaller adipocytes and less total body fat, but also had less lean mass. The amount of body fat relative to body weight of infants fed the diluted formula was similar to that of infants fed the concentrated formula (13 versus $14 \%$ ). In the present study, female infants fed the concentrated formula were heavier, but were not fatter than infants fed normal formula. These findings are consistent with those of Fomon et al. (19). They reported that during the first $9 \mathrm{wk}$ human infants fed a concentrated formula consumed more calories and grew at a greater rate than infants fed a normal formula. They speculated that the extra weight gained by the overfed infants was not lipid. Recently, Roberts et al. (8) reported in a prospective study that reduced energy expenditure measured at 3 mo of age, not caloric intake, was related to increased adiposity measured by skinfold thicknesses measured at 6-9 mo of age. Our results, together with these and other human infant studies $(6,7,9)$, support the view that a high caloric intake does not necessarily result in obese infants (10).

The interpretation that overfeeding with a concentrated for-

Table 2. Effect of infant diet and sire on urinary creatinine excretion, neck skinfold thickness, and crown-rump length*

\begin{tabular}{|c|c|c|c|c|c|c|}
\hline \multirow[b]{2}{*}{ Sire } & \multirow[b]{2}{*}{$\begin{array}{c}\text { Infant } \\
\text { diet }\end{array}$} & \multirow[b]{2}{*}{$n$} & \multicolumn{2}{|c|}{ Urinary creatinine $\dagger$} & \multirow{2}{*}{$\begin{array}{l}\text { Crown- } \\
\text { rump } \\
\text { length } \ddagger \\
\text { (cm) }\end{array}$} & \multirow{2}{*}{$\begin{array}{c}\text { Neck } \\
\text { skinfold } \\
\text { thickness } \\
(\mathrm{mm})\end{array}$} \\
\hline & & & $\mu \mathrm{mol} / \mathrm{d}$ & $\begin{array}{c}\mu \mathrm{mol} / \mathrm{d} / \\
\mathrm{kg}\end{array}$ & & \\
\hline \multirow[t]{2}{*}{$\times 1337$} & $N F$ & 3 & $430 \pm 30$ & $220 \pm 5$ & $9.6 \pm 0.7$ & $1.6 \pm 0.4$ \\
\hline & OF & 2 & $430 \pm 30$ & $250 \pm 5$ & $7.8 \pm 0.5$ & $1.2 \pm 0.5$ \\
\hline \multirow[t]{2}{*}{ X2088 } & NF & 5 & $310 \pm 20$ & $200 \pm 5$ & $8.4 \pm 0.5$ & $2.1 \pm 0.2$ \\
\hline & OF & 4 & $380 \pm 20$ & $220 \pm 5$ & $9.1 \pm 0.3$ & $1.4 \pm 0.3$ \\
\hline \multirow[t]{2}{*}{$X 2378$} & NF & 4 & $330 \pm 20$ & $200 \pm 5$ & $7.8 \pm 0.7$ & $1.7 \pm 0.2$ \\
\hline & OF & 4 & $390 \pm 20$ & $220 \pm 5$ & $8.4 \pm 0.3$ & $2.1 \pm 0.2$ \\
\hline \multicolumn{7}{|l|}{ Effect of } \\
\hline Diet & & & $0.08 \S$ & 0.026 & NS & NS \\
\hline Sire & & & 0.03 & 0.034 & NS & NS \\
\hline Diet/sire & & & NS & NS & 0.042 & NS \\
\hline
\end{tabular}

* Values are means \pm SEM. NF, normal feeding; OF, overfeeding.

$\dagger$ Means of two measurements at 7 and $17 \mathrm{wk}$ of age.

$¥$ Increase from birth until $18 \mathrm{wk}$ of age.

$\S p$ values. 


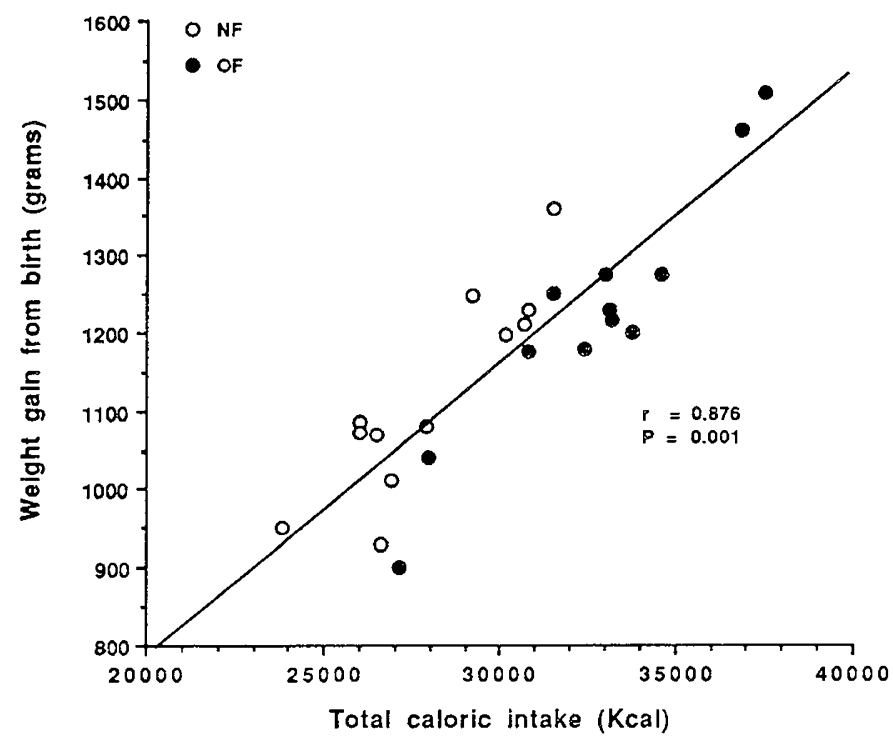

Fig. 5. Relationship of weight gain from birth with total caloric intake. Weight gain is calculated as body weight minus birth weight. The caloric intake is the total calories consumed from birth until weaning at the end of 18 wk of age.

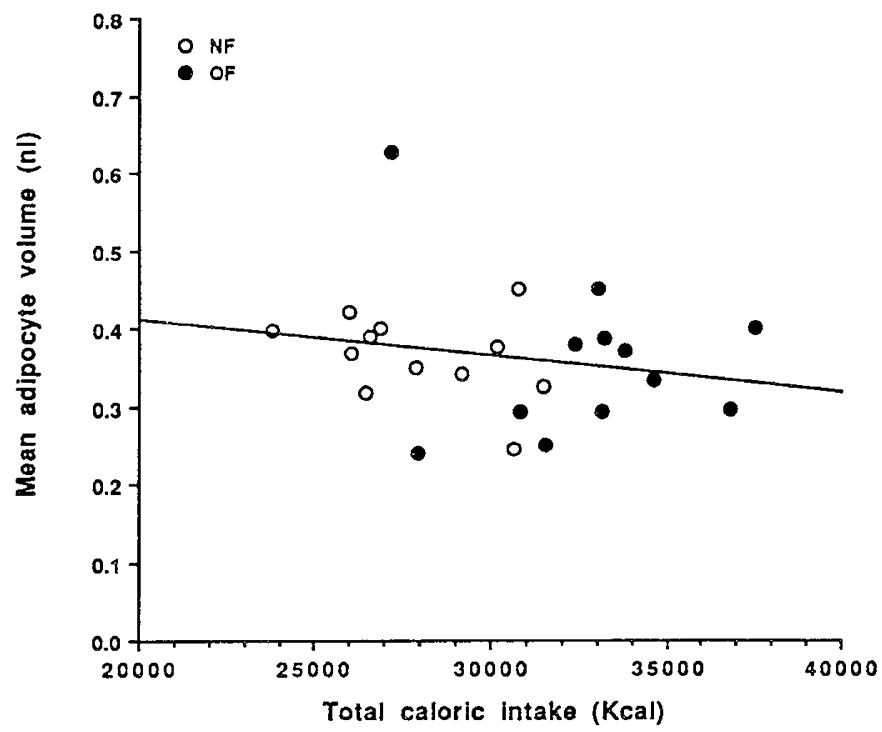

Fig. 6. Relationship of infant mean adipocyte volume with total caloric intake. The values for total caloric intake were calculated as described in Figure 5.

Table 3. Multiple regression analysis of adipocyte volume in infant baboons

\begin{tabular}{ccclcl}
\hline $\begin{array}{c}\text { Depot } \\
\text { site }\end{array}$ & $R^{2}$ & $p$ & $\begin{array}{c}\text { Predicting } \\
\text { variable }\end{array}$ & $\begin{array}{c}\text { Partial } \\
\text { coefficient* }\end{array}$ & $p$ \\
\hline Omentum & 0.334 & 0.026 & Maternal wt & 0.459 & 0.024 \\
& & & Sire & 0.390 & 0.06 \\
Flank & 0.733 & 0.001 & Maternal wt & 0.523 & 0.01 \\
& & & Sire & 0.733 & 0.001 \\
Popliteal & 0.482 & \multirow{2}{*}{0.01} & Maternal wt & 0.523 & 0.01 \\
& & & Sire & 0.483 & 0.027 \\
\hline
\end{tabular}

* Adjusting for caloric intake and either sire identity or maternal weight.

mula compared with feeding a normal formula had no effect on infant adiposity is based on two indirect measurements of body fatness: adipocyte volume and the neck skinfold thickness. We used these measurements for the following reasons: First, it is

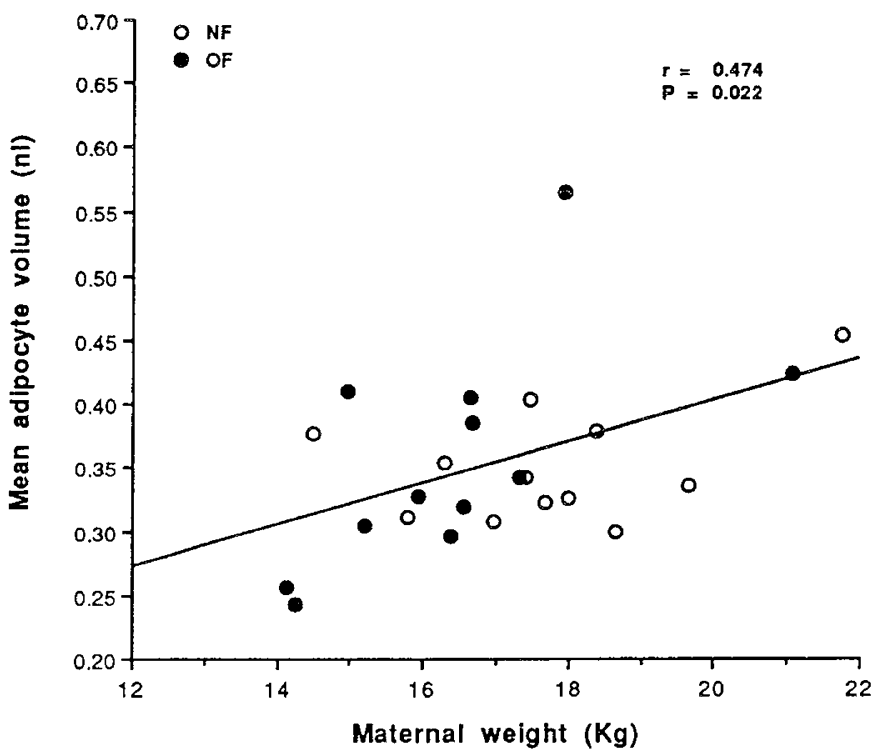

Fig. 7. Relationship between infant mean adipocyte volume and maternal weight. Maternal weight is the mean weight over 3 y before breeding for the current experiment. Values have been adjusted for sire and total caloric intake.

well established that adipocyte volume represents the net deposition of triglyceride into adipocytes and is increased in virtually all types of obesity in humans and animals, including the baboon (14). Second, adipocyte volume strongly reflects total body fat in infant baboons and is strongly correlated with adiposity measured directly (Fig. 1). It is possible that overfeeding increased fat mass by increasing the number of adipocytes and not adipocyte volume. This is not likely to have occurred in the current experiment for the following reasons: First, our previous work indicated that extremes in caloric intake, exceeding those of the current experiment, did not influence adipocyte number in infant baboons at weaning (12). Secondly, the number of adipocytes reported in four infant baboons fed normal formula (20) was similar to the number of adipocytes reported for infants overfed with concentrated formula (12). Finally, the neck skinfold thickness, the only morphometric measure significantly associated with body fat in infant female baboons (16), was not increased in infants overfed with concentrated formula, suggesting that total body fat was not appreciably different between the two infant diet groups.

Overfeeding with a concentrated formula during the preweaning period did not result in infant obesity or even a moderate increase in adiposity. This conclusion is limited in three respects. First, a greater degree of overfeeding than that attained in the current experiment may be necessary to increase body fat during the preweaning period. Infant baboons were overfed using a concentrated formula that provided more protein, fat, and carbohydrate, but in the same proportions and with the same number of meals as the normal formula. The level of overfeeding in the current experiment in terms of percentage of increase in total calories and calories ingested per $\mathrm{kg}$ body weight is comparable to that described in human infants fed a concentrated formula (19). It is possible that overfeeding infants with more meals and with diets of different nutrient composition (i.e. low and high fat) could result in increased fat deposition and obesity. The early introduction of solid food may be more relevant to infant obesity than excessive formula feeding inasmuch as caloric intake is increased to a much greater extent $(4,5)$. Also, higher intakes of fat than that in our experiment may increase fat mass gain in infants because the macronutrient composition of formulas is known to influence the lean and fat mass gain by premature babies $(21-23)$. The second limitation is that genetic background may influence the effect of overfeeding on growth 
and fat development during infancy. There were significant, albeit small, sire by infant diet interactions on adipocyte volume and crown-rump length. These results should be interpreted with caution because of the small numbers of infants and sires. However, they suggest that genetic background may determine the response to overfeeding during infancy. A similar result has been reported recently in 12 pairs of young adult male twins overfed an identical diet for $100 \mathrm{~d}$ (24). In that study, weight gain and visceral fat mass gain were found to be partly due to undefined genetic factors. The third limitation is that male infants may respond differently to overfeeding than females. Both male infant and young adult baboons responded to underfeeding and overfeeding differently from female infants (11-14).

Why overfeeding with concentrated formula had no effect on net fat deposition into adipocytes in the female infant baboon is not known. Infant baboons from birth to $18 \mathrm{wk}$ of age are developmentally similar to human infants from birth to 1 yr of age (17) and like human infants (1) develop considerable amounts of body fat (approximately $25 \%$ of the total preweaning weight gain) during the preweaning period (11). It is possible that such rapid fat development represents maximal utilization of calories available for storage. The increased caloric intake in the infants of this study was apparently diverted into lean tissue growth or dissipated by an increase in metabolic rate induced by overfeeding (25). The higher excretion of total urinary creatinine and creatinine $/ \mathrm{kg}$ body mass in the infant baboons fed concentrated formula compared with the baboons fed normal formula and the association of urinary creatinine with muscle mass (26, 27) suggest that some of the extra weight gained by infants overfed with concentrated formula is muscle mass. The greater increase in crown-rump length in infants overfed with concentrated formula from specific sires suggests that skeletal growth may also be increased by feeding the concentrated formula during infancy.

Influence of sire and maternal weight on infant adipocyte volume. Whether genetic or environmental factors play a greater role in determining fat deposition in individuals is controversial $(28-33)$. Most studies addressing this issue in humans have compared twins as older children and as young adults that have been reared apart. Stunkard et al. (33) have reported substantial genetic influences on body-mass index, whereas the childhood environment had little or no influence. In contrast, environmental factors also contribute to determining individual levels of adiposity in population studies of preschool- and school-age children $(2,30)$.

In the current study, we determined the relative contributions of a single environmental factor (caloric intake), sire group, and maternal weight on adipocyte volume of baboon infants reared under identical environmental conditions in the absence of parental contact. In our experiment maternal weight was positively associated with increased adipocyte volume in the visceral region (omentum) and s.c. sites (flank and popliteal) of infants at $19 \mathrm{wk}$ of age. There was also a strong sire effect on infant adipocyte volume: offspring of X1337, the leanest sire who had half brothers and sisters who were also relatively lean, had smaller adipocytes than did offspring from X2088 and X2378. Sire X2088 also had fatter half brothers and sisters than X1337. Multivariate analysis revealed that, together, maternal weight and sire account for 33 to $73 \%$ of the variability in adipocyte volume depending on the depot site. These observations in the absence of significant influence of caloric intake on adipocyte volume are consistent with a strong genetic control on adipocyte volume during the infant period in the baboon. Identification of the relationship of reduced energy expenditure and increased adiposity by Roberts et al. (8) raises the question of whether the genetic influence is mediated through behavioral or metabolic mechanisms.

Regional difference in adipocyte volume in infants. We found subtle differences in adipocyte volume among the omentum, flank, and popliteal depots in infant female baboons at $19 \mathrm{wk}$ of age. However, neither infant formula nor sire influenced the site differences in adipocyte volume. The omentum is the largest unilateral depot and the flank and popliteal depots are among the smallest depots in both infant and adult baboons $(12,13)$. Much of this regional difference in fat accumulation is due to fat cell number, as in other species (34). The importance of regional differences in adipocyte volume is that large adipocytes in the visceral region are associated with the metabolic aberrations associated with obesity (35). The presence of a significant regional difference in adipocyte volume in infants may predict future fat distribution and, subsequently, susceptibility to obesity-related disease. There are no reports on the ontogenesis of visceral fat depots such as the omentum in primates. Longitudinal study of the infants in the present report will provide information on the changes of regional fat cell volume with age.

Acknowledgments. The authors thank Jimmy Burd, Aixa Kelley, and Ignacio Gomez for expert animal care; Drs. K. D. Carey and Michelle Leland for veterinary assistance; and Diane DeChant and Cheryl Raindl for technical assistance.

\section{REFERENCES}

1. Fomon SJ 1967 Body composition of the male reference infant during the first year of life. Pediatrics 40:863-870

2. Charney E, Goodman H, McBride M, Byon B, Pratt R 1976 Childhood antecedents of adult obesity. Do chubby infants become obese adults? N Engl J Med 295:6-9

3. Eid EE 1970 Follow-up study of physical growth of children who had excessive weight gain in first six months of life. Br Med $\mathbf{J} 2: 74-76$

4. Shukla A, Forsyth HA, Anderson CM, Marwah SM 1972 Infantile overnutrition in the first year of life: a field study in Dudley, Worchestershire. Br Med J 4:507-515

5. Taitz LS 1971 Infantile overnutrition among articially fed infants in the Sheffield region. Br Med J 1:315-316

6. Dubois S, Hill DE, Beaton GH 1979 An examination of factors believed to be associated with infantile obesity. Am J Clin Nutr 32:1997-2004

7. Huenemann RL 1974 Environmental factors associated with preschool obesity. I. Obesity in 6-month-old children. $\mathrm{J}$ Am Diet Assoc 64:480-487

8. Roberts SB, Savage JS, Coward WA, Chew B, Lucas A 1988 Energy expenditure and intake in infants born to lean and overweight mothers. $N$ Engl $J$ Med 318:461-466

9. Rose HE, Mayer J 1968 Activity, calorie intake, fat storage, and the energy balance of infants. Pediatrics 41:18-29

-10. Dwyer JT, Mayer J 1973 Overfeeding and obesity in infants and children. Bibl Nutr Dieta 18:123-152

11. Lewis DS, Bertrand HA, Masoro EJ, McGill Jr HC, Carey KD, McMahan CA 1984 Effect of interaction of gender and energy intake on lean body mass and fat mass gain in infant baboons. J Nutr 114:2021-2026

- 12. Lewis DS, Bertrand HA, Masoro EH, McGill Jr HC, Carey KD, McMahan CA 1983 Preweaning nutrition and fat development in baboons. J Nutr 113:2253-2259

13. Lewis DS, Bertrand HA, McMahan CA, McGill Jr HC, Carey KD, Masoro EJ 1986 Preweaning food intake influences the adiposity of young adult baboons. J Clin Invest 78:899-905

- 14. Lewis DS, Bertrand HA, McMahan CA, McGill Jr HC, Carey KD, Masoro EJ 1989 Influence of preweaning food intake on body composition of young adult baboons. Am J Physiol 257:R1128-R1135

15. DiGirolamo M, Mendlinger S, Fertig JW 1971 A simple method to determine fat cell size and number in four mammalian species. Am J Physiol 221:850858

16. Rutenberg GW, Coelho Jr AM, Lewis DS, Carey KD, McGill Jr HC 1987 Body composition in baboons: evaluating a morphometric method. Am J Primatol 12:275-285

17. Coelho Jr AM 1985 Baboon dimorphism: growth in weight, length, and adiposity from birth to 8 years of age. In: Watts ES (ed) Nonhuman Primate Models for Human Growth and Development. Alan R Liss, New York, pp 125-159

18. Draper NR, Smith H 1966 Applied Regression Analysis. John Wiley \& Sons, New York

19. Fomon SJ, Filer Jr LF, Thomas LN, Rogers RR, Proksch AM 1969 Relationship between formula concentration and rate of growth of normal infants. J Nutr 98:241-254

20. Masoro EJ 1980 Obesity development, aging. In: Kalter SS (ed) The Use of Nonhuman Primates in Cardiovascular Disease. University of Texas Press, Austin, TX, pp 334-356

- 21. Kashyap S, Schulze KF, Forsyth M, Zucker C, Dell RB, Ramakrishnan R, Heird WC 1988 Growth, nutrient retention, and metabolic response in low birth weight infants fed varying intakes of protein and energy. $J$ Pediatr 113:713-721

22. Reichman B, Chessex P, Verellen G, Putet G, Smith JM, Heim T, Swyer PR 1983 Diet macronutrient storage in preterm infants. Pediatrics 72:322-328

23. Schulze KF. Stefanski M. Masterson J. Spinnazola R. Ramakrishnan R, Dell 
RB, Heird WC 1987 Energy expenditure, energy balance, and composition of weight gain in low birth weight infants fed diets of different protein and energy content. J Pediatr 110:753-759

- 24. Brouchard CA, Tremblay A, Despres J-P, Nadeau A, Lupien PJ, Theriault G, Dussault J, Mooijani S, Pinault S, Fournier G 1990 The response to longterm overfeeding in identical twins. N Engl J Med 322:1477-1482

25. Danforth Jr E, Burger A 1984 The role of thyroid hormones in the control of energy expenditure. Clin Endocrinol Metab 13:58 l-593

26. Forbes GB, Bruining GJ 1976 Urinary creatinine excretion and lean body mass. Am J Clin Nutr 29:1359-1366

27. Meador CK, Kreisberg RA, Friday Jr JP, Bowdoin B, Coan P, Armstrong J, Hazelrig JB 1968 Muscle mass determination by isotopic dilution of creatine14C. Metabolism 17:1104-1108

28. Annest JL, Sing CF, Biron P, Mongeau JG 1983 Familial aggregation of blood pressure and weight in adoptive families. III. Analysis of the role of shared genes and shared household environment in explaining family resemblance for height, weight, and selected weight/height indices. Am J Epidemiol 117:492-506

29. Börjeson M 1976 The aetiology of obesity in children. A study of 101 twin pairs. Acta Paediatr Scand 65:279-287

30. Dietz Jr WH, Gortmaker SL 1984 Factors within the physical environment associated with childhood obesity. Am J Clin Nutr 39:619-624

31. Garn SM, Cole PE, Bailey SM 1977 Effect of parental fatness levels on the fatness of biological and adoptive children. Ecol Food Nutr 6:91-94

32. Hartz A, Giefer E, Rimm AA 1977 Relative importance of the effect of family environment and heredity on obesity. Ann Hum Genet 41:185-193

33. Stunkard AJ, Sorensen TIA, Hanis C, Teasdale T, Charkraborty R, Schull WJ Schulsinger F 1986 An adoption study of human obesity. N Engl J Med 314:193-198

34. Leibel RL, Edens NK, Fried SK 1989 Physiologic basis for the control of body fat distribution in humans. Annu Rev Nutr 9:417-443

35. Krotkiewski M, Björntrop P, Sjöstrom L, Smith U 1983 Impact of obesity on metabolism in men and women. Importance of regional adipose tissue distribution. J Clin Invest 72:1 150-1162

\section{Announcement}

\section{Call for Abstracts}

The American Pediatric Society and The Society for Pediatric Research announce the abstract deadline for the 1992 Annual Meeting (May 4-7, 1992, Convention Center, Baltimore, MD) has been set as January 3, 1992. For further information, contact: APS/SPR, 141 Northwest Point Blvd., P.O. Box 675, Elk Grove Village, IL 60009-0675, (708)427-0205, FAX (708)427-1305. 